\title{
A SUCESSÃO EM PROPRIEDADES RURAIS FAMILIARES DE FREDERICO WESTPHALEN/RS: INFLUÊNCIAS E DIRECIONAMENTOS DECISÓRIOS DOS ATORES
}

\author{
A SUCCESSION IN RURAL PROPERTIES FAMILY OF \\ FREDERICO WESTPHALEN/RS: INFLUENCES AND \\ GUIDELINES DECISION MAKING OF ACTORS
}

\author{
Fernando Panno \\ Universidade Federal de Santa Maria/Campus de Frederico Westphalen - Frederico Westphalen - \\ RS - Brasil \\ João Armando Dessimon Machado \\ Universidade Federal Rio Grande do Sul - Porto Alegre - RS - Brasil
}

\begin{abstract}
Resumo: $O$ presente artigo objetiva discutir a sucessão hereditária em pequenas propriedades rurais familiares sob a ótica da teoria da decisão, considerando especialmente o processo decisório, aos quais passam potenciais sucessores (filhos) e sucedidos (pais), e os diferentes fatores que os influenciam neste processo. Para a análise empírica, considerou-se uma amostra de 50 agricultores familiares do município de Frederico Westphalen/RS, uma vez que o meio rural do Município é predominantemente formado por pequenas propriedades familiares e, ao longo do tempo, tem passado por constantes transformações em função do êxodo jovem, fato que vem acarretando uma série de problemas sociais e econômicos ao desenvolvimento rural local. Para mensurar essa realidade, foram aplicados questionários aos agricultores e seus potenciais sucessores.
\end{abstract}

Palavras chave: Agricultura Familiar. Sucessão Hereditária. Tomada de Decisão, Desenvolvimento Rural.

Abstract: This article discusses the hereditary succession in small family farms, from the perspective of decision theory, especially considering the decision making process, which become potential successors (children) and successful (parents) considering the different factors that influence this process. For the empirical analysis, it was considered a sample of 50 farmers in the municipality of Frederico Westphalen / RS, since the rural municipality medium is predominantly made up of small family farms and, over time, has undergone constant changes due youth exodus, a fact that is causing a number of social and economic problems to local rural development. To measure this reality questionnaires were applied to farmers and their potential successors.

Keywords: Family Farming. Hereditary Succession. Decision Making. Rural Development.

\section{Introdução}

O acesso à tecnologia da informação, com ferramentas como a internet, telefone celular e televisão por assinatura, defronta os jovens do século XXI com um mundo globalizado e repleto de atrativos que estão ao alcance de suas mãos. Da mesma forma, a ampliação das possibilidades de estudo, com a expansão universitária, oportuniza a muitos jovens uma formação acadêmica até então distante de seus sonhos.

Esse cenário, vislumbrado pela juventude rural, tem-se tornado cada vez mais urbano, o que gera um fenômeno iniciado com a modernização da agricultura e intensificado com as tecnologias e inovações, a evasão juvenil do meio rural, que seguem seus rumos direcionados pelos benefícios e facilidades dos centros urbanos, tornando crescente o desejo dos jovens de não reproduzir as 
atividades dos pais na pequena propriedade (SILVESTRO; CORTINA, 1998). Esse fator tem alterado significativamente a estrutura do meio rural, com mais ou menos intensidade.

A diminuição do êxodo jovem e alternativas que viabilizem a sucessão dessas terras faz parte desse processo de reconstrução de um espaço muitas vezes desacreditado, fazendo com que a agricultura familiar e sua essência baseada na interação entre gestão e trabalho com mão de obra familiar encontre dificuldades em garantir a sua reprodução social. Essa dificuldade está intimamente relacionada ao constante e crescente desinteresse da população rural jovem, especialmente feminina, de permanecer no campo.

Conforme Camarano e Abramovay (1998), na década de 1990, a saída da população do campo concentra-se na faixa etária mais jovem (homens tinham de 20 a 24 anos e as mulheres de 15 a 19), com maior proporção de moças. Essa realidade se intensificou na última década, especialmente com a expansão das possibilidades de formação acadêmica para estes jovens.

Esse fenômeno, quando afeta regiões com economia predominantemente agrícola, pode trazer consequências preocupantes, que se ampliam quando a região é caracterizada pela agricultura estruturada em moldes familiares, muitas propriedades com pequenas quantidades de terras, como é o caso da região de Frederico Westphalen-RS, situada geograficamente no Médio Alto Uruguai do Rio Grande do Sul, a última a ser colonizada no estado (BERNARDES, 1997). A agricultura familiar é uma importante mola propulsora de desenvolvimento econômico e social para o município de Frederico Westphalen.

Segundo o Instituto Brasileiro de Geografia e Estatística - IBGE (1991), no ano de 1980, 30,2\% dos jovens de Frederico Westphalen, cerca de 2.900 jovens entre 15 e 29 anos, viviam no meio rural, destes, 52,4\% eram homens e 47,6\% mulheres. À medida que a população rural foi diminuindo no município, a quantidade de jovens também diminuiu, em uma proporção maior que a queda populacional geral. Já a divisão de gênero mostrou-se relativamente constante até o final do século XX. O censo de 1991 apontou uma população rural jovem de $24,3 \%$, sendo que $53,4 \%$ era do sexo masculino e $46,6 \%$ do sexo feminino. No censo agropecuário de 1996, esta diferença foi mantida, com 53,3\% de jovens do sexo masculino e $46,7 \%$ de jovens do sexo feminino vivendo no meio rural do município, no entanto, o universo da população jovem no rural caiu para $21,6 \%$.

O cenário passa a sofrer modificações mais significativas no século XXI. Enquanto, no censo de 2000, a população rural representava $23,6 \%$ da população total do município, em 2010 este percentual caiu para 19,10\%. Essa queda, se analisada proporcionalmente ao número de habitantes que deixaram o campo, chega a $15 \%$ em 10 anos.

No entanto, a situação rural local é agravada pela intensidade com que a população rural jovem vem decrescendo. Segundo o censo do IBGE 2010, neste ano, a população rural jovem no Município de Frederico Westphalen era de $16,9 \%$. Ou seja, em 30 anos, houve uma queda de 13,3\% no número de população jovem no meio rural local. É uma taxa importante, considerando que muitos dos jovens atrelados ao meio rural pelo censo não desenvolvem atividades na propriedade, estudando e/ou trabalhando na cidade, diminuindo ainda mais a mão de obra ativa. 
Além disso, é perceptível que houve uma migração maior de mulheres do que de homens para os centros urbanos nesse período. Enquanto os índices se mantiveram próximos até o final do século XX, no ano de 2010, a população rural jovem do Município de Frederico Westphalen contava com cerca de $40 \%$ de mulheres e $60 \%$ de homens. Os números passam a apontar um dos problemas identificados quando são abordadas as motivações acerca da sucessão hereditária de pequenas propriedades rurais, especialmente o envelhecimento da população rural e a masculinização, expressa pelas manifestações dos jovens quanto à dificuldade de contrair matrimônio, tido como um dos principais empecilhos para permanecer no campo.

Outro fator passível de análise e que tende a influenciar e/ou motivar as decisões sobre sucessão é o tamanho das propriedades. Esse é um fator importante e compõe o perfil social/familiar do jovem potencial sucessor, e também auxilia na justificativa e comprovação da realidade da agricultura minifundiária de Frederico Westphalen/RS, que tem na agricultura uma de suas principais fontes de riqueza e é composta por pequenas propriedades rurais familiares.

O presente estudo busca conhecer as percepções dos potenciais sucessores (filhos) e sucedidos (pais) sobre sucessão, bem como elaborar um parecer sintetizado dos fatores influenciadores dos direcionamentos decisórios destes atores, que acabam condicionando suas predisposições sobre o tema e, de certa forma, conduzindo os rumos da agricultura familiar em pequenas propriedades rurais. O Município de Frederico Westphalen/RS foi o campo de estudos empírico escolhido para tratar o assunto, pelas suas características rurais alicerçadas na agricultura familiar.

\section{Teoria da decisão: processo voltado à agricultura familiar}

Uma contextualização da teoria da decisão parte do entendimento da decisão como um processo onde o ser humano planeja, desenvolve e executa ações, consciente ou inconscientemente, que refletem seus hábitos, valores e comportamento. Para Simon (1965), as decisões são pautadas pela ação do momento, que possui uma qualidade imperativa, orientando o comportamento rumo à alternativa escolhida pela seleção de situações futuras em detrimento de outro e pela descrição do futuro estado das coisas, que por sua natureza pode ser verdadeira ou falsa, pode se confirmar ou não.

A teoria da decisão, na concepção de Simon (1965) é uma teoria comportamental administrativa. Está intimamente relacionada aos preceitos administrativos, focada na estrutura de análise de situações voltadas à gestão empresarial de atividades práticas que envolvem tanto o decidir como o fazer, numa junção de processos de decisão e de ação que vai além da ideia de que a tomada de decisão se limita à formulação de política geral da organização (SIMON, 1965). Apesar disso, a Teoria da Decisão extrapola as barreiras empresariais e adentra em áreas e situações cotidianas do ser humano, de escolha, comportamento, juízos de valor e de fatos que vão além dos limites da racionalidade e da relatividade.

Dessa forma, a teoria da decisão oportuniza ao agente decisor, seja ele um gestor empresarial ou um pequeno produtor rural, um planejamento do futuro da sua empresa ou propriedade, vislumbra uma gama importante de dados, que 
permite compreender o conhecimento, distribuição de probabilidades, alternativas de ação disponíveis e consequências de eventos futuros (ANDRADE, 2010). Esse planejamento é parte de um processo que envolve escolhas e geralmente são influenciadas por uma série de fatores internos e externos, micro e macroambientais.

O processo decisório está presente no dia a dia das pessoas, como escolhas, sendo que estas aprendem por tentativa e erro ou por um conjunto de habilidades de tomada de decisão, que incluem a busca por informações relevantes. Esse processo passa a ser condicionante para que as consequências das decisões tomadas sejam pré-visualizadas e absorvidas pelos atores, uma vez que acontecem dentro de um ambiente volátil e incerto (DALCIN, 2013).

A tomada de decisão na organização (ou instituição) é bastante clara e pode ser percebida empiricamente em qualquer análise (FREITAS, 1997). Diante da problemática da sucessão hereditária na agricultura familiar, a tomada de decisão do pequeno produtor é condicionante para o futuro, não só da propriedade, mas também da agricultura familiar como um todo. $O$ processo pelo qual a família passa é complexo, envolve fatores cognitivos que vão além de aspectos econômicos e empresariais.

\section{Tomada de decisão na agricultura familiar}

A realidade da agricultura nacional passa por constantes transformações e, em meio aos grandes produtores e o mercado, está o pequeno agricultor, que, com suas próprias forças, luta dia pós dia para manter-se no campo, apesar de todas as projeções e indicativos o expulsarem de seu habitat. Esta realidade começa a tomar rumos mais otimistas, na medida em que "instituições, públicas e privadas, participam do desenvolvimento do campo através de políticas de incentivo, ações e programas desenhados para proteger a renda rural" (ZYLBERSZTAJN; NEVES, 2000, p. 07), gerando alternativas de manutenção das famílias no meio rural, oportunizando a estas famílias alternativas de agregar valor à sua produção e, consequentemente, prosperar com a terra.

A globalização da economia mundial transformou a agricultura em sua essência. Da atividade voltada para a autossuficiência da propriedade, a agricultura modernizou-se, adequando-se à evolução da economia de mercado (ARAÚJO; WEDEKIN; PINAZZA, 2001). Essas alterações de cotidiano, mudanças gradativas dos meios de produção, associadas aos atrativos urbanos, culminaram com um redesenho do rural, fazendo com que os agricultores tomem suas decisões, das mais corriqueiras às mais complexas, considerando uma série de influências e predicados.

O grau de complexidade de uma decisão depende dos elementos disponíveis para o processo decisório, dos riscos inerentes e das consequências que esta decisão trará para o futuro do decisor. Na agricultura, as decisões cotidianas, de plantio, aplicação de insumos, colheita e mercado, podem adquirir status mais ou menos complexos, dependendo do volume de produção e da representatividade econômica dessa produção para a família. Dalcin (2013) enfatiza que tradição, aprendizado, infraestrutura, fatores psicológicos, sociais e econômicos são componentes presentes nas decisões dos agricultores, 
especialmente os familiares, que têm um sentimento de pertencimento ligado à terra e, geralmente, demonstram menores tendências à mudança.

As decisões que permeiam o processo sucessório na agricultura familiar adquirem caráter, em muitos casos, definitivos e condicionantes ao futuro das pequenas propriedades rurais. Para Lobley (2010), a identificação de um sucessor pode agir como um gatilho para o desenvolvimento dos negócios, assim como a existência de um potencial sucessor pode ser uma forte motivação para investimentos na propriedade (negócio), mesmo tendo o agricultor uma idade avançada e prestes a se aposentar (LOBLEY, 2010). O autor complementa dizendo que, apesar de o impacto da sucessão ser de difícil mensuração até que o sucessor assuma a propriedade, a antecipação e expectativa de sucessão podem influenciar a tomada de decisão, uma vez que indica a continuidade da prática.

\section{Agricultura Familiar e Sucessão Hereditária}

O Ministério do Desenvolvimento Social - MDS define agricultura familiar como uma forma de produção onde predomina a interação entre gestão e trabalho. É o agricultor familiar que dirige o processo produtivo, dando ênfase à diversificação e utilizando o trabalho familiar, eventualmente complementando com o trabalho assalariado. Schneider (2003) complementa afirmando que, para se definir agricultura familiar, não se pode levar em consideração apenas as atividades econômicas associadas à produção agropecuária da família, deve-se olhar o agricultor familiar sob uma ótica da pluriatividade, atividades externas executadas pelos membros da família, que não descaracteriza a agricultura familiar.

Embora o termo "agricultura familiar" seja comumente usado, tanto na literatura científica como no meio popular, não existe uma definição comum para caracterizar as explorações familiares em todo o mundo. Estas definições, muitas vezes incluem dois critérios: (1) a propriedade da terra ou direitos de posse da terra ao longo de gerações e (2) o uso de mão de obra familiar (VLIET, 2015). São pautadas em decisões, tanto de posse e direito de uso da terra e, consequentemente, preparação de sucessores quanto de usos de mão de obra familiar, que em detrimento das vantagens fundamentais atreladas a este meio de produção não pode ficar de fora da caracterização.

Para Errington e Gasson (1994), a centralidade das relações da família e o envolvimento direto do chefe da propriedade e de seus familiares nas suas atividades diárias caracterizam esta propriedade como familiar, ao contrário de unidades não familiares, nas quais há uma separação entre propriedade, gestão e trabalho. Outros fatores como rentabilidade da propriedade e existência ou não de renda provenientes de atividades não agrícolas, podem estar inseridos como fatores determinantes na definição de agricultura familiar.

Essa agricultura familiar, importante força motriz da economia em diversas partes do mundo, vem sendo ameaçada por fenômenos e situações pertinentes. $O$ êxodo rural e principalmente o desinteresse dos jovens em permanecer no meio é uma realidade preocupante. Os jovens do campo estão deixando as terras dos pais para tentarem a sorte na cidade, acarretando a super população destas, com o intuito de estabelecerem-se nos estudos ou em outras atividades, muitas vezes incentivados pelos pais. 
[...]cada vez mais, os pais põem seus filhos na escola, mesmo que tenham que deslocá-los para a cidade para continuarem estudando. Parece que não querem mais que seus filhos sejam também agricultores, e os jovens filhos dos agricultores tão pouco parecem pensar em ser agricultores no futuro (PIRAN, 2001, p.134).

Estudos desenvolvidos sob essa ótica apontam que dentre os aspectos responsáveis por essa realidade está a falta de perspectivas entre estas pessoas de buscar uma oportunidade melhor e prosperar com a terra, uma vez que os incentivos dados a sua permanência no meio rural, apesar de crescentes, ainda são pouco atrativos perante as oportunidades oferecidas pelas áreas urbanas. Outro fator determinante, segundo Segatti e Hespanhol (2008), é o avanço da tecnologia na agropecuária e crescente dependência aos complexos agroindustriais, que exercem forte pressão sobre os pequenos produtores rurais, sendo necessária a ampliação de meios para fonte de renda, baseadas na diversificação das atividades na propriedade.

Essa pressão provoca, especialmente nos mais jovens, o desejo de consolidar-se profissionalmente em ambientes que thes proporcionem uma aproximação com aquilo que eles consideram e exaltam como difusores de qualidade de vida e dignidade. Para Grubbström et al (2014), sabe-se que o futuro da agricultura está nas mãos das gerações futuras de agricultores, e uma questão chave para que se tenha a continuidade deste processo é que estes jovens tenham condições de se relacionar e se adaptar aos processo de mudança em curso no setor agrícola. Ou seja, a agricultura deve ser considerada como uma alternativa profissional para essa nova geração.

Considerando o pressuposto de que a agricultura familiar continua a ser, quase exclusivamente, uma ocupação hereditária, em que a transferência do controle da propriedade para a próxima geração é, sem dúvida, uma das fases mais críticas para o desenvolvimento do negócio, (LOBLEY, 2010), especialmente na pequena propriedade rural, os encaminhamentos sucessórios dentro da própria família tornam-se fundamentais para a continuidade da agricultura familiar.

A sucessão de uma propriedade rural ou negócio familiar é um processo formado por três componentes: a transferência patrimonial, a continuação da atividade profissional paterna e a retirada das gerações mais velhas do comando do negócio. São decisões bilaterais e, muitas vezes, conflituosas (ABRAMOVAY, 2001). Dentre os aspectos centrais desse processo, a transferência de posse tende ser o mais delicado, uma vez que geralmente envolve mais de um interessado direto e, a estes interessados (filhos), ainda podem-se somar terceiras pessoas (cônjuges). Outro fator delicado é a retirada das gerações mais velhas do comando do negócio, a delegação de autoridade e responsabilidade nesse processo pode não ser fácil, especialmente para o sucedido.

Dessa forma, a manutenção das atividades familiares nas pequenas propriedades vai além do interesse dos proprietários e da adequação destes às tendências tecnológicas e comerciais, partindo da motivação e visualização de futuro de seus sucessores. Adachi (2006, p.199) lembra que o processo de sucessão "estará associado a duas disposições de vontade: o sucedido deve ceder sua posição e o sucessor deve assumir o novo posto". Percebe-se que o caminho sucessório tem duas vias paralelas, de interesse e vontade mútuos. 
A sucessão de atividades entre membros da família, parte da real intenção do sucedido de transferir as funções aos sucessores, segue na preparação desses e culmina com o encaminhamento da sucessão incluindo as novas gerações nos processos decisórios, gerenciais e cotidianos da propriedade (CASILLAS et al, 2007). O fato de que "o sucessor ideal deve ser um indivíduo que contemple todas as habilidades necessárias para assumir um cargo importante" (ADACHI, 2006, p. 204) parte de uma série de ações de responsabilidade compartilhada.

A problemática da sucessão hereditária não é uma particularidade das propriedades agrícolas, apesar destas apresentarem situações mais propensas para que se tenha falta de sucessores, especialmente as propriedades menores, com características familiares. A sucessão é tema preocupante também quando se fala em empresa familiar. Nesse sentido, os estudos científicos existentes que abordam o tema da sucessão hereditária em organizações familiares e as perspectivas que direcionam estas empresas familiares à sucessão podem ser adaptados à realidade das pequenas propriedades familiares, principalmente por adentrarem no processo decisório desta perspectiva e considerar a importância e necessidade de uma consistente análise dos fatores ambientais e holísticos que interferem neste processo.

Ao abordar as decisões sobre investimentos na propriedade, tomadas pelos agricultores familiares de modo geral, dentro de uma perspectiva estratégica, Vliet et al (2015) afirmam que a presença de um sucessor na família, acaba influenciando positivamente o interesse dos pais por investimentos financeiros mais complexos. Já agricultores sem sucessor, muitas vezes se aposentam na propriedade e começam a reduzir gradualmente as atividades e o investimento na propriedade.

Dessa forma, os autores salientam que os agricultores com sucessão tendem a investir na propriedade, aumentando sua rentabilidade econômica, em muitos casos, adquirindo terras de vizinhos sem sucessor. Essa prática de investimento acaba contribuindo para que o interesse sucessório dos jovens, já vistos pelos pais como sucessores, aumente e a sucessão se confirme.

\section{Procedimentos metodológicos}

O presente estudo tem um caráter investigativo e analítico, uma vez que parte da busca sistemática da solução de um problema, gerando conhecimentos úteis para pleitear a solução destes BOAVENTURA (2004). No caso, trata-se da constante diminuição de perspectivas e interesse sucessório para a agricultura familiar. A região de estudos empíricos foi predefinida e delimitada com base em suas características rurais, com predominância de pequenas propriedades familiares. O intuito do estudo é investigar as similaridades ou dissonâncias nas decisões dos atores acerca da sucessão hereditária, contrapondo com as teorias propostas.

Contudo, para contemplar e atingir os objetivos propostos nesta investigação, foram elencadas ferramentas e propostas metodológicas. O plano de coleta de dados do presente estudo, por seu caráter investigativo e analítico, propõe a utilização de dados primários e secundários, para abordar a temática. Os dados primários foram coletados basicamente por meio de um questionário Survey, baseado no interrogatório dos participantes. Os dados secundários foram 
organizados a fim de elucidar o desconhecido que tem relação com a temática. Foram analisados indicadores socioeconômicos com o auxilio especialmente dos censos estatísticos do IBGE, além das informações disponíveis em órgãos rurais, bibliografias e documentos.

\subsection{Delimitação da área geográfica para coleta dos dados empíricos}

Considerando a contemporaneidade e importância do tema proposto no presente estudo, a delimitação dos atores que representação a amostra empírica do mesmo tem um papel crucial na construção científica de respostas para a problemática e objetivos propostos. A figura 1 delimita o Município de Frederico Westphalen/RS como espaço geográfico e demográfico para a amostra empírica por apresentar características significativas e diretamente relacionadas ao escopo da presente proposta, ou seja, a predominância de agricultores familiares. Trata-se de um município considerado pequeno em termos populacionais e geográficos, mas com grande importância econômica, social e educacional para uma das regiões mais enfraquecidas economicamente do Estado do Rio grande do Sul (CHIARINI, 2008).

Figura 1. Localização geográfica do Município de Frederico Westphalen/RS

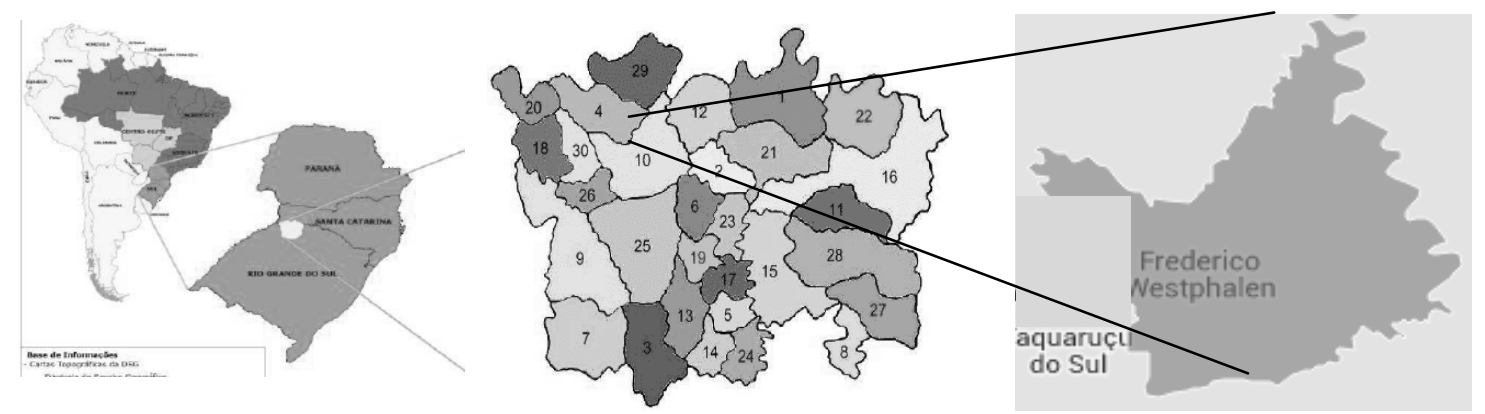

Fonte: Elaborado pelo autor a partir de mapas do IBGE, CODEMAU e URI, 2015.

O Município de Frederico Westpahlen está localizado na Mesorregião Noroeste do Estado do Rio Grande do Sul. É sede, o maior e mais significativo município do Conselho Regional de Desenvolvimento do Médio e Alto Uruguai COREDE CODEMAU do RS. A economia do município está alicerçada no comércio e especialmente na agricultura, sendo que, a realidade do meio rural local é de pequenas propriedades rurais, com média de 17 hectares.

Frederico Westphalen se destaca também como um polo educacional, com a presença de quatro universidades, duas públicas (Universidade Federal de Santa Maria - UFSM campus de Frederico Westphalen e Universidade Estadual do Rio Grande do Sul - UERGS), uma comunitária (Universidade Regional Integrada URI) e uma particular de ensino a distância (Universidade do Norte do Paraná UNOPAR). Além desses centros universitários, o município é sede de um centro do Instituto Federal Farroupilha e de uma Casa Familiar Rural, que trabalha com a pedagogia da alternância, cujo principal objetivo é formar jovens para atuação na propriedade familiar, tornando-os sucessores naturais. 


\subsection{Coleta de Dados e Seleção da Amostra}

No campo empírico, onde dados fazem uma sobreposição às teorias na consolidação dos objetivos do estudo, foram coletadas informações junto a agricultores familiares do Município de Frederico Westphalen/RS, cujos valores pessoais e padrões de decisão acerca do futuro da propriedade são analisados e interpretados. Foram aplicados questionários (survey) idênticos aos potenciais sucedidos (responsável pela propriedade) e potenciais sucessores (jovens). O confronto de tais informações apresenta um aparato das motivações e tendências decisórias destes atores, com relação à sucessão da propriedade e, consequentemente, ao futuro dela.

Para compor a amostra, entendeu-se como potencial sucessor o jovem, independente do gênero - masculino ou feminino -, com mais de 15 anos de idade e que estivesse residindo na propriedade rural em tempo parcial ou integral. Por tais jovens, compreendeu-se aqueles que não se desvincularam totalmente da propriedade e que não tenham recebido parcela de terra para si. Aos potenciais sucessores que compuseram a amostra, não foram impostas condições de estudo. Alguns tiveram oportunidade de estudar em níveis mais elevados, outros tiveram oportunidade de frequentar escolas voltadas para as práticas agrícolas e outros não. Essa particularidade também foi interpretada e mostrou-se importante para a estrutura decisória desses jovens.

De acordo com Levin (1987), a seguinte fórmula é capaz de apontar, de forma simples, a quantidade de elementos que são necessários para que as informações levantadas sejam relevantes e confiáveis, considerando a margem de erro amostral predeterminada.

Fórmula para o cálculo do tamanho da amostra:

$$
\begin{aligned}
& \mathrm{NO}=1 / \mathrm{EO}^{2} \\
& n=(N \cdot N O) /(N+N O)
\end{aligned}
$$

Sendo que:

$$
\begin{aligned}
& \mathrm{n}=\text { tamanho da amostra } \\
& \mathrm{N}=\text { Tamanho da população } \\
& \mathrm{NO}=\text { primeira aproximação do tamanho da amostra } \\
& \mathrm{EO}=\text { erro amostral tolerável }
\end{aligned}
$$

A quantidade de propriedades familiares de pequenos agricultores de Frederico Westphalen com potenciais sucessores pode ser estimada, mas não precisamente definida. Para se chegar a um número aproximado dessa população, foram considerados os números, mesmo que desatualizados, do último censo do IBGE (2010), que apontam uma população total de 1.064 famílias com mais de dois membros. Dessas famílias, mesmo sendo compostas por três ou mais pessoas, muitas não contam com potenciais sucessores, tem filhos menores de 15 anos e outras são compostas por idosos ou são propriedades utilizadas exclusivamente como residência, não têm produção ou práticas agrícolas.

De acordo com profissionais da Secretaria de Agricultura, do Sindicato dos Trabalhadores Rurais e da Empresa de Assistência Técnica e Extensão Rural EMATER do município, pessoas que conhecem profundamente a realidade rural local, bem como a formação familiar destes agricultores, cerca de $40 \%$ das propriedades rurais têm potenciais sucessores dentro das características preestabelecidas (426 propriedades). Diante das projeções de população e, 
considerando-se um nível de confiabilidade de $86 \%$, chegou-se ao tamanho mínimo da amostra:

$$
\begin{aligned}
& N 0=1 / 0,142 \\
& N 0=51,02 \\
& n=(426.51,02) /(426+51,02) \\
& n=(21.734,52) /(477,02) \\
& n=45,56
\end{aligned}
$$

Aplicando a regra estatística a uma população de 426 propriedades com potenciais sucessores, com um nível de confiabilidade de $86 \%$, chega-se a uma amostra mínima de 46 propriedades. Considerando a amostra mínima, e com o intuito de alocar uma margem maior a esta população, foram aplicados 50 questionários aos potenciais sucessores e o mesmo número aos sucedidos, para que se obtenham resultados comparativos. Dessa amostra, para compor a opinião dos jovens, foram considerados somente os potenciais sucessores que já têm uma decisão previamente tomada, pela sucessão ou não. Os indecisos (10 respondentes) foram excluídos da amostra.

A escolha das famílias que compuseram a amostra teve caráter não probabilístico, sendo que a escolha das famílias se deu por indicação dos técnicos agrícolas da unidade da EMATER local e técnicos da prefeitura, que atendem a secretaria municipal da agricultura, por conhecerem bem as famílias e, consequentemente, por saberem quais delas têm os predicados e características necessárias para representar a população total. Foram consideradas, além das características já mencionadas, uma heterogeneidade de localização geográfica, de condições econômicas financeiras e de infraestrutura das propriedades para que a amostra fosse o mais fidedigna possível da população.

\section{Resultados e discussões}

Com a perspectiva de compreender a intensidade com que determinadas situações e formas de pensar dos atores (sucessores e sucedidos) influenciam nas decisões sobre sucessão e direcionam para a existência ou não de sucessor geracional, foram elaborados quadros e análises originadas do levantamento de dados empíricos, coletados junto aos agricultores familiares de Frederico Westphalen/RS, que compuseram a amostra do presente estudo. As visões de potenciais sucessores (filhos) e sucedidos (pais) são analisadas separadamente, abrindo a possibilidade de comparação entre elas, uma vez que as concepções acerca do rural, suas particularidades e projeções, tendem a ser dissonantes em alguns aspectos e consonantes em outros, nos perfis geracionais.

Além de analisar as percepções geracionais, a amostra de potenciais sucessores foi dividida entre os jovens que se dizem decididos pela sucessão e os que estão decididos pela não permanência na propriedade, apesar de, no momento da coleta dos dados, estarem residindo nela. Os jovens que se mostraram indecisos, que estão avaliando as possibilidades e alternativas, ou esperando definições sobre seu futuro para decidir, não entraram nas referidas análises. Dessa forma, a amostra composta por 40 jovens que demonstraram um posicionamento decisório sobre a sucessão ficou composta por 26 que pretendem permanecer na propriedade e 14 que possivelmente não ficarão. 


\subsection{Influências dos aspectos de formação pessoal e profissional}

O processo sucessório geracional de pequenas propriedades rurais tem sofrido alterações ao longo do tempo. As motivações dessas alterações estão especialmente ligadas ao avanço tecnológico na produção agropecuária e, na região foco do estudo, ao crescente aumento de possibilidades no campo educacional. Com a facilidade de aprimoramento acadêmico, nos vários níveis (médio, técnico, tecnológico e superior), os jovens passaram a vislumbrar oportunidades além da porteira da propriedade dos pais, pois os atrativos urbanos Ihes foram apresentados. Os filhos mais novos passaram a ter nos estudos novas perspectivas, que acabaram afastando-os do interesse sucessório.

Vê-se na região uma gama significativa de oportunidades de aperfeiçoamento acadêmico que intensifica essa realidade. A presença de diversas instituições, públicas e privadas, ofertando cursos superiores, tecnológicos e técnicos, especialmente na área agrícola, possibilita aos jovens da região a abertura de horizontes diferentes daqueles vislumbrados por seus pais na sua juventude. Esse cenário tem apontamentos positivos e negativos na ruralidade. Oportuniza aos jovens do campo qualificação que, quando aplicada de maneira coerente dentro das propriedades, gera bons resultados, mas também lhes apresenta um mundo dinâmico que, por vezes, afasta-os do interesse em continuar com as atividades familiares.

Nesse sentido, os quadros 1 e 2 apresentam as visões de potenciais sucessores (filhos) e sucedidos (pais) acerca da influência dos estudos e de aperfeiçoamento educacional e profissional nas decisões que permeiam a sucessão. Percebe-se que, nas perspectivas sobre o tema, apesar de apresentar divergências importantes, pais e filhos têm visões lineares acerca dos prós e contras da ascensão educacional para a manutenção da agricultura familiar dentro de uma perspectiva sucessória.

Quadro 1. O quanto a formação acadêmica e aperfeiçoamento profissional motivam os jovens para sucessão. Visão dos sucessores (FILHOS)

\begin{tabular}{|l|c|c|c|c|c|}
\hline \multicolumn{1}{|c|}{ FATORES } & $\begin{array}{c}\text { Motiva } \\
\text { Muito } \\
(\%)\end{array}$ & $\begin{array}{c}\text { Motiva } \\
(\%)\end{array}$ & $\begin{array}{c}\text { Indif. } \\
(\%)\end{array}$ & $\begin{array}{c}\text { Motiva } \\
\text { Pouco } \\
(\%)\end{array}$ & $\begin{array}{c}\text { Não } \\
\text { motiva } \\
(\%)\end{array}$ \\
\hline Formação em ensino médio não agrícola & - & 6 & 12 & 48 & 34 \\
\hline $\begin{array}{l}\text { Formação em ensino médio agrícola } \\
\text { (formando técnicos agrícolas) }\end{array}$ & 8 & 14 & 46 & 32 & - \\
\hline $\begin{array}{l}\text { Formação em ensino médio agrícola (não } \\
\text { formando técnico agrícola) }\end{array}$ & 38 & 54 & 8 & - & - \\
\hline Formação superior em área agrícola & 2 & 36 & 28 & 32 & 2 \\
\hline Formação superior em área não agrícola & & 4 & 50 & 28 & 18 \\
\hline $\begin{array}{l}\text { Participação em cursos de curta duração na } \\
\text { área agrícola }\end{array}$ & 16 & 42 & 32 & 10 & - \\
\hline $\begin{array}{l}\text { Participação periódica em feiras e } \\
\text { exposições do setor agropecuário }\end{array}$ & 66 & 32 & 2 & - & - \\
\hline $\begin{array}{l}\text { Fazer parte da diretoria de associações, } \\
\text { sindicatos e cooperativas agrícolas }\end{array}$ & 8 & 22 & 40 & 26 & 4 \\
\hline $\begin{array}{l}\text { Participar de entidades de fomento como } \\
\text { associado ou membro }\end{array}$ & 26 & 48 & 26 & - & - \\
\hline
\end{tabular}

Fonte: Dados da pesquisa. 
Quadro 2. O quanto a formação acadêmica e aperfeiçoamento profissional motiva o jovem para sucessão. Visão dos sucedidos (PAIS)

\begin{tabular}{|l|c|c|c|c|c|}
\hline \multicolumn{1}{|c|}{ FATORES } & $\begin{array}{c}\text { Motiva } \\
\text { Muito } \\
(\%)\end{array}$ & $\begin{array}{c}\text { Motiva } \\
(\%)\end{array}$ & $\begin{array}{c}\text { Indif. } \\
(\%)\end{array}$ & $\begin{array}{c}\text { Motiva } \\
\text { Pouco } \\
(\%)\end{array}$ & $\begin{array}{c}\text { Não } \\
\text { motiva } \\
(\%)\end{array}$ \\
\hline Formação em ensino médio não agrícola & & 2 & 28 & 40 & 30 \\
\hline $\begin{array}{l}\text { Formação em ensino médio agrícola } \\
\text { (formando técnicos agrícolas) }\end{array}$ & 16 & 48 & 32 & 4 & - \\
\hline $\begin{array}{l}\text { Formação em ensino médio agrícola (não } \\
\text { formando técnico agrícola) }\end{array}$ & 82 & 18 & - & - & - \\
\hline Formação superior em área agrícola & 12 & 52 & 28 & 8 & - \\
\hline Formação superior em área não agrícola & & & 10 & 36 & 54 \\
\hline $\begin{array}{l}\text { Participação em cursos de curta duração na } \\
\text { área agrícola }\end{array}$ & 64 & 36 & - & - & - \\
\hline $\begin{array}{l}\text { Participação periódica em feiras e } \\
\text { exposições do setor agropecuário }\end{array}$ & 88 & 12 & - & - & - \\
\hline $\begin{array}{l}\text { Fazer parte da diretoria de associações, } \\
\text { sindicatos e cooperativas agrícolas }\end{array}$ & 4 & 40 & 50 & 6 & - \\
\hline $\begin{array}{l}\text { Participar de entidades de fomento como } \\
\text { associado ou membro }\end{array}$ & - & 32 & 52 & 14 & 2 \\
\hline
\end{tabular}

Fonte: Dados da pesquisa.

A principal divergência entre as opiniões de sucessores e sucedidos sobre a influência dos estudos nas decisões sobre sucessão geracional encontra-se nas oportunidades de cursar algo voltado ao setor agropecuário, seja em nível técnico, tecnológico ou superior. Um índice significativo de potenciais sucessores (Quadro 1) considera que esses cursos acabam motivando pouco o jovem a permanecer na pequena propriedade. Dentre os jovens entrevistados, 34\% acreditam que uma formação superior em área agrícola motiva pouco ou não motiva os jovens a permanecer na propriedade, enquanto que $28 \%$ se dizem indiferentes. No mesmo sentido, esses jovens acreditam que a conclusão do ensino médio ou tecnológico, com o título de técnicos agrícolas ou agropecuários, também gera pouca motivação para a sucessão, 78\% entre indiferentes e pouca motivação.

Já os potenciais sucedidos (pais) têm uma visão diferente dos resultados dessas oportunidades, voltados à permanência dos jovens na propriedade (QUADRO 2). Os números mostram que $72 \%$ deles acreditam que, quando encaminham os filhos para cursar uma faculdade na área agrícola, são grandes as chances de estes retornarem para aplicar seus conhecimentos no desenvolvimento da propriedade. Da mesma forma, quando os filhos saem para cursar ensino médio em escola agrícola formadora de técnicos, $64 \%$ entendem que esta formação poderá motivá-los e prepará-los para enfrentar os desafios da agricultura familiar.

Essas diferenças de percepção podem estar ocasionando conflitos de interesses pouco percebidos na família uma vez que o jovem sai para estudar sabendo que poderá ser um processo sem retorno, ou seja, busca formação agrícola, mas sem a intenção de desempenhar as habilidades e conhecimentos adquiridos na propriedade familiar. E os pais, por sua vez, incentivam os filhos ao estudo, em muitos casos, na esperança que estes possam retornar mais capazes de gerir as atividades dentro da propriedade da família.

Outras diferenças de percepção, entre sucessores e sucedidos, são as motivações que cursos de curta duração na área agrícola e a sua participação em entidades de fomento exercem nas decisões dos jovens pela sucessão. Apesar de ambos acreditarem que esses cursos possam motivar os jovens a ficarem, os pais 
acreditam que eles influenciam e motivam muito seus filhos pela permanência. Já os filhos não veem essas influências com a mesma intensidade, $42 \%$ dos jovens acham que os cursos de curta duração não são tão relevantes na construção de uma postura sucessória de sucesso e apenas 16\% deles acreditam que eles motivam muito. Já $64 \%$ dos pais atrelam grande importância a esses cursos e entendem que eles acabam motivando muito os jovens à sucessão.

Apesar das diferenças de posição nos fatores supracitados, pais e filhos têm um pensamento linear e consonante quanto à influência da formação dos jovens em escolas de ensino médio e cursos universitários que não são voltados ao setor agropecuário. Ambos são enfáticos em afirmar que, quando os jovens saem para cursar uma faculdade em área não agrícola, eles dificilmente retornarão para as atividades da propriedade. Nesse caso, percebe-se que os pais têm essa certeza de forma mais clara que os filhos. Dentre os pais entrevistados, 90\% acreditam que um curso superior em qualquer área que não esteja ligada à agricultura motiva pouco ou nada os jovens a buscar a sucessão.

No mesmo sentido, as duas gerações concordam que a formação de ensino médio, em escolas agrícolas que não formam técnicos agropecuários, acaba motivando bastante estes jovens a permanecerem na propriedade familiar e preparando-os para a sucessão. Nesse caso, a contribuição da Casa Familiar Rural, existente no campo de estudos empíricos, tem um papel importante na consolidação da agricultura familiar na região e na preparação de jovens para que, no futuro, possam assumir e dar continuidade às atividades da propriedade familiar.

Por fim, os quadros 1 e 2 mostram que sucessores e sucedidos são incisivos em afirmar que a participação e envolvimento periódico dos jovens com feiras e exposições agropecuárias são excelentes fatores motivacionais para que queiram manter-se na pequena propriedade. Segundo eles, esses eventos acabam apontando aos jovens alternativas reais palpáveis de desenvolver a propriedade familiar com qualidade de vida, minimizando os problemas e desafios que os afasta dali. Neles, são apresentadas aos jovens novidades em termos de tecnologias, técnicas produtivas e de manejo, alternativas de gestão e de aumento de produtividade, que os motiva a pensar na sucessão.

\subsection{Influências dos aspectos estruturais, sociais, econômicos e pessoais}

Considerando que uma parcela de jovens vem buscando motivação, seja nos estudos ou em fatores diversos para permanecer no campo e construir suas vidas na pequena propriedade familiar, os quadros que seguem foram elaborados de acordo com os apontamentos de interesse sucessório dos 50 jovens entrevistados. O Quadro 3 apresenta uma série de fatores que possam vir a influenciar a decisão desses jovens sobre a sucessão e foi composto por aqueles que se dizem interessados em permanecer na propriedade. Já o quadro 4 é composto pelos apontamentos dos jovens que, apesar de ainda estarem residindo na propriedade rural, estão decididos a não permanecer nela e atrelam graus de influências de certos fatores que motivam a sua decisão. 
Quadro 3. Grau de influência dos fatores nas decisões sobre sucessão. Visão dos sucessores (filhos) que estão dispostos a permanecer na propriedade

\begin{tabular}{|l|c|c|c|c|c|}
\hline \multicolumn{1}{|c|}{ FATORES } & $\begin{array}{c}\text { Influen. } \\
\text { Muito } \\
(\%)\end{array}$ & $\begin{array}{c}\text { Influen. } \\
(\%)\end{array}$ & $\begin{array}{c}\text { Indif. } \\
(\%)\end{array}$ & $\begin{array}{c}\text { Influen. } \\
\text { Pouco } \\
(\%)\end{array}$ & $\begin{array}{c}\text { Não infl. } \\
(\%)\end{array}$ \\
\hline Infraestrutura na propriedade & 76,9 & 23,1 & - & - & - \\
\hline Quantidade de terras & 42,3 & 53,9 & & 3,8 & - \\
\hline Qualidade da terra & 65,4 & 30,8 & 3,8 & - & - \\
\hline Retorno financeiro & 88,5 & 11,5 & - & - & - \\
\hline Disponibilidade de mão de obra & 3,8 & 34,7 & 50 & 11,5 & - \\
\hline Distância da cidade & 3,8 & 57,7 & 30,8 & 7,7 & - \\
\hline Transporte até a cidade & - & 27 & 65,4 & 3,8 & 3,8 \\
\hline Acesso às tecnologias & 23,1 & 61,6 & 11,5 & - & 3,8 \\
\hline Opções de lazer & 15,4 & 65,4 & 15,4 & 3,8 & - \\
\hline Possibilidades de matrimônio & 26,9 & 30,8 & 38,5 & 3,8 & - \\
\hline Incentivo dos pais & 76,9 & 19,3 & 3,8 & - & - \\
\hline Políticas públicas de incentivo & 23,1 & 53,9 & 19,2 & 3,8 & - \\
\hline Comercialização da produção & 69,2 & 30,8 & & - & - \\
\hline Preço dos produtos agrícolas & 65,4 & 26,9 & 7,7 & - & - \\
\hline Entidades (Coop. Sindic. Assoc.) & 3,8 & 50 & 27 & 15,4 & 3,8 \\
\hline Assistência técnica especializada & 7,7 & 46,1 & 34,7 & 11,5 & - \\
\hline Participação nas decisões da propriedade & 84,6 & 15,4 & - & - & - \\
\hline Acesso à informação & 38,5 & 46,1 & 7,7 & 7,7 & - \\
\hline Acesso a crédito rural & 38,5 & 46,1 & 15,4 & - & - \\
\hline Disponibilidade de escolas agrícolas & 42,3 & 30,8 & 23,1 & 3,8 & - \\
\hline Valorização social do agricultor & 23,1 & 46,1 & 27 & 3,8 & - \\
\hline Fonte: Dados da pesquisa. & & & & - \\
\hline
\end{tabular}

Fonte: Dados da pesquisa.

Dentre os jovens que, em princípio, apontam o interesse pela sucessão, os fatores que mais se destacam estão ligados, além do retorno financeiro, apontado como principal fator, aos aspectos familiares, de relacionamento interpessoal entre as gerações, tanto nas questões voltadas às práticas cotidianas dentro da propriedade como nas motivações diretas da família para que os jovens queiram permanecer na propriedade. A pesquisa aponta que $84,6 \%$ desses jovens sentemse muito motivados a permanecerem no campo quando têm abertura para participar das decisões dentro da propriedade. Os outros 15,5\% também se dizem motivados quando lhes é dada abertura para participar das decisões. Tem-se, nesse ponto, um aspecto importante que compõe o processo sucessório, e deve contar com a perspicácia dos chefes da propriedade que queiram encontrar um sucessor para que compreendam a importância de incluir os filhos no dia a dia dela.

Da mesma forma, outra motivação vinda da família condiz com os incentivos dos pais. Dos jovens propensos à sucessão, $96 \%$ se dizem motivados ou muito motivados a permanecer na propriedade quando são incentivados pelos pais. Esses apontamentos mostram que, para que haja interesse sucessório por parte dos jovens, os pais devem estar interessados e motivados na formação de um sucessor. No entanto, em pergunta aberta feita aos pais sobre sua satisfação com a vida no campo, alguns nutrem um duplo sentimento. Ao mesmo tempo em que gostariam que a propriedade continuasse nas mãos da família, com os filhos sucedendo-os e fazendo a propriedade prosperar, entende que a sua geração sofreu com as dificuldades do campo e não gostariam que seus filhos passassem pelas mesmas dificuldades. 
Considerando aspectos estruturais e de mercado, têm-se importantes fontes de motivação para a sucessão. A infraestrutura da propriedade e a qualidade da terra, bem como os fatores mercadológicos, de preço e comercialização dos produtos agrícolas, a quantidade de terra, a disponibilidade de escolas agrícolas, bem como acesso ao crédito rural e à informação, também são importantes para o êxito de um processo sucessório.

Percebe-se como ponto comum entre esses fatores mais considerados, a possibilidade de gerir a propriedade com técnicas modernas, intensificando o processo produtivo. Ou seja, os jovens propensos a permanecerem no campo, buscam, além do incentivo familiar e autonomia nas decisões, infraestrutura para produção, terras de qualidade, acesso ao crédito e à informação para que possam se estabelecer de forma competitiva no setor.

Fatores como a possibilidade de matrimônio, opções de lazer e acesso às tecnologias também são considerados, apesar de menos expressivos na escala de motivação para a permanência no campo. São fatores que estão diretamente ligados aos objetivos de vida e pessoais da maioria dos jovens, assim como a valorização social do agricultor. Já disponibilidade de mão de obra, distância e transporte até a cidade, fazer parte de entidades e receber assistência técnica foram considerados menos importantes no momento de uma escolha futura.

Quadro 4. Grau De influência dos fatores nas decisões sobre sucessão. Visão dos sucessores (filhos) que NÃO estão dispostos a permanecer na propriedade.

\begin{tabular}{|l|c|c|c|c|c|}
\hline \multicolumn{1}{|c|}{ FATORES } & $\begin{array}{c}\text { Influen. } \\
\text { Muito } \\
(\%)\end{array}$ & $\begin{array}{c}\text { Influen. } \\
(\%)\end{array}$ & $\begin{array}{c}\text { Indif. } \\
(\%)\end{array}$ & $\begin{array}{c}\text { Influen. } \\
\text { Pouco } \\
(\%)\end{array}$ & $\begin{array}{c}\text { Não infl. } \\
(\%)\end{array}$ \\
\hline Infraestrutura na propriedade & 64,3 & 35,7 & - & - & - \\
\hline Quantidade de terras & 42,9 & 50 & 7,1 & - & - \\
\hline Qualidade da terra & 64,3 & 28,6 & 7,1 & - & - \\
\hline Retorno financeiro & 78,6 & 21,4 & - & - & - \\
\hline Disponibilidade de mão de obra & - & 28,6 & 42,9 & 21,4 & 7,1 \\
\hline Distância da cidade & 7,1 & 35,7 & 35,7 & 21,4 & - \\
\hline Transporte até a cidade & 28,6 & 42,9 & 14,3 & 14,3 & - \\
\hline Acesso às tecnologias & - & 71,4 & 14,3 & 14,3 & - \\
\hline Opções de lazer & 21,4 & 21,4 & 35,7 & 21,4 & - \\
\hline Possibilidades de matrimônio & 28,6 & 35,7 & 21,4 & 7,1 & 7,1 \\
\hline Incentivo dos pais & 50 & 35,7 & 14,3 & - & - \\
\hline Políticas públicas de incentivo & - & 42,9 & 50 & 7,1 & - \\
\hline Comercialização da produção & 28,6 & 64,3 & - & 7,1 & - \\
\hline Preço dos produtos agrícolas & 71,4 & 14,3 & 7,1 & 7,1 & - \\
\hline Entidades (Coop., sindic. Assoc.) & - & 28,6 & 50 & 7,1 & 14,3 \\
\hline Assistência técnica especializada & - & 35,7 & 42,9 & 14,3 & 7,1 \\
\hline Participação nas decisões da propriedade & 64,3 & 21,4 & 14,3 & - & - \\
\hline Acesso à informação & 14,3 & 57,1 & 14,3 & 14,3 & - \\
\hline Acesso a crédito rural & 14,3 & 57,1 & 21,4 & 7,1 & - \\
\hline Disponibilidade de escolas agrícolas & 28,6 & 57,1 & 7,1 & - & 7,1 \\
\hline Valorização social do agricultor & 21,4 & 50 & 14,3 & 14,3 & - \\
\hline
\end{tabular}

Fonte: Dados da pesquisa.

Considerando os fatores que possam vir a motivar os potenciais sucessores a ficarem no campo, apresentados nos quadros 3 e 4, percebe-se uma convergência de opiniões. Constatou-se que a decisão sobre permanecer ou não tende a estar diretamente ligada à realidade atual de cada jovem. Ou seja, se a propriedade familiar tem uma boa infraestrutura, se a terra é de qualidade, se o 
jovem tem uma boa abertura para participar das decisões e são incentivados pelos pais a permanecer, as chances de existência de um sucessor na família são grandes. Com isso, haverá maior propensão de melhores resultados financeiros, maior competitividade no mercado e acesso às informações, fatores igualmente importantes para os jovens.

As maiores diferenças de percepção entre os jovens decididos pela sucessão e os que se afastam dela estão na distância da terra até a cidade e no acesso às tecnologias. Essas questões dizem respeito às facilidades de fazer chegar o conforto tecnológico encontrado nos centros urbanos até a propriedade e também a facilidade de estar mais próximo da cidade, por vezes, com a possibilidade de residir nela e trabalhar no campo, ou ainda do sucessor trabalhar no campo e o cônjuge na cidade.

\section{3 Opiniões comparadas: entre potenciais sucessores e sucedidos}

Ao atribuir um grau de influência na motivação dos jovens pela permanência ou não na propriedade familiar, de acordo com os sucedidos (QUADRO 5), considerando os mesmos fatores analisados pelos jovens, vê-se similaridades nas respostas, mas também são percebidas lacunas entre as ponderações das duas gerações. São considerados, na amostra 41, pais, potenciais sucedidos, que afirmam ter ou não um sucessor definido, ou seja, aqueles que já têm uma decisão sobre sucessão encaminhada.

Quadro 5. Grau de influência dos fatores nas decisões sobre sucessão. Visão dos sucedidos (pais)

\begin{tabular}{|l|c|c|c|c|c|}
\hline \multicolumn{1}{|c|}{ FATORES } & $\begin{array}{c}\text { Influen. } \\
\text { Muito } \\
(\%)\end{array}$ & $\begin{array}{c}\text { Influen. } \\
(\%)\end{array}$ & $\begin{array}{c}\text { Indif. } \\
(\%)\end{array}$ & $\begin{array}{c}\text { Influen. } \\
\text { Pouco } \\
(\%)\end{array}$ & $\begin{array}{c}\text { Não infl. } \\
(\%)\end{array}$ \\
\hline Infraestrutura na propriedade & 68,3 & 29,3 & 2,4 & - & - \\
\hline Quantidade de terras & 41,5 & 53,7 & 4,9 & - & - \\
\hline Qualidade da terra & 53,7 & 46,5 & - & - & - \\
\hline Retorno financeiro & 92,7 & 7,3 & - & - & - \\
\hline Disponibilidade de mão de obra & - & 24,4 & 53,1 & 19,5 & - \\
\hline Distância da cidade & 2,5 & 41,5 & 41,5 & 14,6 & - \\
\hline Transporte até a cidade & - & 26,8 & 48,8 & 19,5 & 4,9 \\
\hline Acesso às tecnologias & 7,3 & 58,5 & 31,7 & 2,4 & - \\
\hline Opções de lazer & 2,4 & 34,1 & 53,7 & 9,8 & - \\
\hline Possibilidades de matrimônio & 65,9 & 29,3 & 4,9 & - & - \\
\hline Incentivo dos pais & 36,6 & 48,8 & 14,6 & - & - \\
\hline Políticas públicas de incentivo & 31,7 & 56,1 & 12,2 & - & - \\
\hline Comercialização da produção & 39 & 48,8 & 9,8 & 2,4 & - \\
\hline Preço dos produtos agrícolas & 75,6 & 19,5 & 4,9 & - & - \\
\hline Entidades (Coop., sindic. Assoc.) & 2,4 & 43,9 & 51,2 & 2,4 & - \\
\hline Assistência técnica especializada & 2,4 & 61 & 36,6 & - & - \\
\hline Participação nas decisões da propriedade & 41,5 & 34,1 & 22 & 2,4 & - \\
\hline Acesso à informação & 2,4 & 68,3 & 26,8 & 2,4 & - \\
\hline Acesso a crédito rural & 24,4 & 51,2 & 19,5 & 4,9 & - \\
\hline Disponibilidade de escolas agrícolas & 12,2 & 51,2 & 36,6 & - & - \\
\hline Valorização social do agricultor & 17 & 41,5 & 41,5 & - & - \\
\hline
\end{tabular}

Fonte: Dados da pesquisa.

Os patriarcas concordam que a maior motivação está no retorno financeiro: $92,7 \%$ responderam que este fator motiva muito os jovens a permanecerem, ou 
seja, número superior ao dos jovens. Outros fatores consonantes nas respostas de sucessores e sucedidos apontam para uma visão singular de como o rural está sendo percebido nos dias atuais. Isso demonstra que a leitura de cenários que está sendo feita nesses fatores é a mesma e as percepções de atrelar uma importância maior ou menor a cada fator são similares.

No entanto, percebem-se algumas análises controversas importantes e que podem se tornar decisivas quando se pensa a sucessão hereditária. A dissonância de valores ou importância atrelada a determinados fatores que motivam as decisões dos atores são significativas na compreensão do resultado final do processo sucessório ou falta dele. Um exemplo disso está na percepção da influência da qualidade da terra como fator motivacional para a sucessão. Enquanto os potenciais sucessores afirmam considerar muito esse fator, os pais mostram uma consideração menor. Essa visão pode estar associada às suas experiências passadas, de trato da terra, ou seja, de adaptação à realidade que se apresentava no momento.

Com relação às políticas públicas de incentivo, os jovens mostram-se desacreditados e caracterizam este fator como menos importante na escala de motivação, se comparado ao índice dos pais. Os pais, aparentemente, esperam mais das entidades fomentadoras de políticas públicas, considerando que estas instituições têm um papel importante na busca de alternativas para a manutenção da agricultura familiar por meio do incentivo à sucessão.

Percebe-se que, apesar de pontos em comum, citados anteriormente, pais e filhos têm visões diferentes em alguns pontos importantes. Para a maioria dos pais $(65,9 \%$ ) a possibilidade de matrimônio influencia muito e outros $29,3 \%$ também acreditam na influência deste fator como motivador para que os jovens queiram permanecer no campo. Considerando a tendência da masculinização no meio rural, e a consequente carência de jovens do sexo feminino que queiram permanecer no campo, percebe-se a geração de um problema de interesse sucessório por parte dos homens, segundo os pais. Já os filhos não atrelam ao fator a mesma importância, apesar de revelarem índices relativamente altos na escala.

Dentre todos os fatores mencionados nos quadros, os que mais chamam a atenção, pela dissonância de perspectivas entre as gerações, estão ligados ao relacionamento pessoal e profissional entre pais e filhos. Os jovens afirmam que o incentivo dos pais é um fator amplamente determinante para o interesse sucessório, 76,9\% dos jovens interessados pela sucessão sentem-se muito motivados por este fator (QUADRO 3). No entanto, apenas 36,6\% dos pais atrelam seus incentivos ao interesse sucessório dos filhos. Os números afirmam a necessidade de diálogo familiar para se chegar a uma decisão sobre sucessão e também deflagram o receio dos pais em influenciar uma decisão dos filhos, que eles próprios não têm certeza que seja a melhor.

Por fim, outro fator determinante que pode mudar os rumos dos processos decisórios relacionados à sucessão é a delegação de responsabilidade e autoridade dada aos filhos dentro do empreendimento familiar. Os potenciais sucessores reiteram a importância de receber autonomia e participar das decisões do dia a dia da propriedade. Dentre os interessados pela sucessão, 84,6\% (QUADRO 3) se dizem muito motivados a ficar na propriedade quando participam ativamente das decisões internas dela. No entanto, apesar da maioria dos pais acharem que o fator 
é motivador, apenas $41,5 \%$ deles considera essas decisões compartilhadas no grau máximo da escala.

A dificuldade dos pais em compreender que os filhos estão aptos a participarem de forma mais enfática e direta das atividades da propriedade, e que estes, por sua vez, esperam receber estas responsabilidades, podem estar sendo decisivas para o futuro desta propriedade. A falta de abertura com relação aos negócios e dividendos financeiros acaba desmotivando os jovens, fazendo com que busquem essas autonomias, tanto financeira quanto de estima e realização, em outros espaços.

\section{CONCLUSÕES}

Assim como em outras regiões com as mesmas características minifundiárias, a crescente desmotivação dos jovens em permanecer nas propriedades familiares passam a gerar problemas sociais e econômicos importantes. O êxodo jovem, com intensidade no gênero feminino, está ocasionando um aumento do envelhecimento e masculinização da população rural e, consequentemente, vem dificultando o processo sucessório e as perspectivas de continuidade das atividades agrícolas.

A percepção que os agricultores têm de sua situação, finalidades e do futuro de sua propriedade acabam direcionando suas decisões e impulsionam as decisões de seus descendentes. Segundo Mann (2004), a escolha dos jovens por permanecer na propriedade familiar e suceder seus pais é fortemente influenciada pelas circunstâncias econômicas e ambientais dos sistemas e cenários agrícolas em que estão inseridos, bem como as diretrizes do setor no momento da decisão. Essa análise temporal e macroambiental deve ser considerada. Dessa forma, o estudo elencou uma série de fatores que acabam influenciando potenciais sucessores e sucedidos em suas decisões.

O fator que mais influencia e motiva os jovens a permanecer na propriedade, atribuído como aspecto fundamental no processo decisório, foi a possibilidade de retorno financeiro que a propriedade pode the oportunizar. Esses jovens, possivelmente, já têm uma atuação mais incisiva nas atividades da família e percebem que o retorno financeiro que a propriedade pode the oferecer dificilmente será alcançado com uma atividade fora dali.

A infraestrutura da propriedade também foi bastante lembrada, corroborando com a ideia de que em uma estrutura adequada, com os negócios geridos com técnicas de gestão, com delegação de responsabilidade e de autoridade, cria-se um ambiente favorável à sucessão. Aspectos de comercialização da produção e o incentivo dos pais também geram interesse sucessório por parte dos jovens.

Já os potenciais sucessores, que neste momento não demonstram interesse na sucessão das atividades familiares, também apontam o retorno financeiro como principal influenciador da sua decisão, mas com menos intensidade. Ao contrário do grupo anterior, estes possivelmente não estão vislumbrando na propriedade as condições de independência econômica que almejam. Isso pode estar vinculado à infraestrutura (também considerada importante) e organização das propriedades desses jovens. Talvez a carência de investimento, de condições de trabalho de métodos de gestão e divisão das atividades e dos dividendos possa estar 
contribuindo para esse posicionamento, uma vez que a participação nas decisões, ou falta dela, aparece como um forte influenciador de conduta decisória.

Talvez se estabeleça, neste raciocínio, um dos gargalos identificados na problemática da sucessão hereditária. Os atores não veem a sucessão como um processo, que precisa ser planejado, discutido e traçado. Imaginam a sucessão como um acontecimento imediato, cuja decisão deve ser tomada quando o chefe da propriedade não puder mais administrá-la, por incapacidade física, doença ou morte. Logicamente, os potenciais sucessores mais jovens precisam amadurecer suas intenções para decidir, mas o processo decisório deve iniciar logo, para que se pense num planejamento sucessório adequado.

Esse processo é conduzido pelas características endógenas dos atores, moldadas e alimentadas pelas situações e condições micro e macroambientais em que vivem. Dessa forma, é natural que haja diferenças de motivações e perspectivas sucessórias em diferentes regiões agrícolas, assim como o processo decisório sobre sucessão é conduzido pelas características econômicas, sociais e políticas locais.

\section{REFERÊNCIAS}

ABRAMOVAY, R. (Coord.). Os impasses sociais da sucessão hereditária na agricultura familiar. Florianópolis: Epagri, Brasília: Nead/ Ministério do Desenvolvimento Agrário, 2001;

ADACHI, P. P. Família S.A.: gestão de empresa familiar e solução de conflitos. São Paulo: Atlas, 2006.

ANDRADE, Janice Jung. Os valores e as motivaçôes no processo de tomada de decisão dos produtores rurais no município de Sant'Ana do Livramento/RS. 2010. 288 f. Tese (Programa de Pós-Graduação em Desenvolvimento Rural) Universidade Federal do Rio Grande do Sul, Porto Alegre, 2010.

ARAÚJO, N. B.; WEDEKIN, I.; PINAZZA, L. A. Complexo agroindustrial: o complexo "agribusiness" brasileiro. Rio de Janeiro: suma economia, 2001;

BERNARDES, N. Bases geográficas do povoamento do Estado do Rio Grande do Sul. Ijuí: Unijuí, 1997.

BOAVEnTURA, E. M. Metodologia da Pesquisa: monografia, dissertação e tese. São Paulo: Atlas, 2004.

CAMARANO, A. A.; ABRAMOVAY, R. Êxodo rural, envelhecimento e masculinização no Brasil: panorama dos últimos cinqüenta anos. Revista Brasileira de Estudos de População, 15(2): 45-66, 1998.

CASILLAS, J. C. B. et al. Gestão da empresa familiar. conceitos, casos e soluções. São Paulo: Thomson, 2007. 
CHIARINI, Tulio. A pobreza no espaço: uma aplicação para o Rio Grande do Sul, 2000. 2008. 125f. Dissertação (Programa de Pós-Graduação em Economia) Universidade Federal do Rio Grande do Sul, Porto Alegre, 2008.

DALCIN, D. Tese de doutorado apresentada ao programa de pós graduação em Agronegócio da UFRGS. Os Estilos de tomada de Decisão e o Desempenho Econômico das propriedades Rurais de palmeira das Missões/RS. Porto Alegre: UFRGS, 2013;

ERRINGTON, A.; GASSON, R. Labour use in the Farm Family Business. Sociology Rural. v. 34, p. 293-307, 1994.

FREITAS, H. et. al. Informação e Decisão: sistemas de apoio e impacto. Porto Alegre: Ortiz, 1997;

GRUBBSTRÖM, A.; STENBACKA, S.; JOOSSE, S. Balancing family traditions and business: Gendered strategies for achieving future resilience among agricultural students. In: Journal of Rural Studies. Department of Social and Economic Geography: Ekonomikum, p. 152 e 161, 2014. Box 513, SE-751 20 Uppsala, Sweden.

IBGE - Sinopse do Censo Demográfico de 1991. Disponível em: <http://biblioteca.ibge.gov.br/vizualizacao/monografias/GEBIS\% 20-

20RJ/CD1991/CD_1991_sinopse_preliminar_RS.pdf>. Acesso em: 11 nov. 2015

IGBE - Instituto Brasileiro de Geografia Estatística. Censo Estatístico 2000 e 2010. Disponível em: <www.ibge.gov.br>. Acesso em: 13 ago. 2014.

LEVIN, J. Estatística Aplicada a Ciências Humanas. 2a . Ed. São Paulo: Arbra Ltda., 1987.

LOBLEY, M. Succession in the family farm business. Journal of Farm Management. v.13. n. 12, p. $839-851,2010$.

MANN, S. Tracing the process of becoming a farm successor on Swiss family farms. Agriculture and Human Values v. 24, Ettenhausen, Switzerland, p. 435443, 2007.

PIRAN, N. Agricultura Familiar: lutas e perspectivas no Alto Uruguai. Erechim: Edifapes, 2001.

SCHNEIDER, S. Teoria Social, Agricultura Familiar e Pluriatividade. Revista Brasileira de Ciências Sociais. Vol.18 N.51. São Paulo. Fevereiro, 2003.

SEGATTI, S.; HESPANHOL, A. N. Alternativas para a geração de renda em pequenas propriedades rurais. In. 4. Encontro Nacional de Grupos de Pesquisa ENGRUP: São Paulo, p.615-631, 2008. 
SILVESTRO, M.L.; CORTINA, N. Desenvolvimento rural sem jovens? Agropecuária Catarinense. 11 (4): 5-8, 1998.

SIMON, H. Comportamento Administrativo. 3 ed. Rio de Janeiro: FGV, 1965;

VLIET, J. A. V.; Et al. De-mystifying family farming: Features, diversity and trends across the globe. In.: Global Food Security, v. 5, p. 11-18, 2015.

ZYLBERSZTAJN, D.; NEVES, M. F. (org). Economia e Gestão dos Negócios Agroalimentares. São Paulo: Pioneira, 2000.

Submetido em 30/05/2016

Aprovado em 23/07/2016

Sobre os autores

Fernando Panno

Doutorando no Programa de Desenvolvimento Rural na UFRGS. Professor da UFSM- Campus de Frederico Westphalen.

E-mail:fpanno@ufsm.br

João Armando Dessimon Machado

Doutor. Professor do Programa de Desenvolvimento Rural da UFRGS.

E-mail: João.dessimon@ufrgs.br 